earlier, around 1941. A similar birth cohort effect is seen in incidence. ${ }^{8}$ There is little evidence for this particular effect in our study perhaps because Scottish women are less at risk than their English and Welsh contemporaries or perhaps because the risk can be largely negated by an effective screening programme.

Women reaching the age of 50 may welcome release from the cervical screening programme as they embark on the breast screening programme. It is not known whether the increasing uptake of hormone replacement therapy will maintain the higher incidence of cervical intraepithelial neoplasia seen in younger women by rejuvenating the cervix and a prospective randomised trial would be warranted.

We thank Dr K A Hussein in the cytopathology laboratory, Dundee Royal Infirmary, Margaret Bell in gynaecological cancer registry, Ninewells Hospital, Wilma Paterson in the Maryfield Computer Centre, and their colleagues for their close cooperation at all times.
1 Scottish Health Service Planning Council. Report on the cervical cytology service in Scotland by ad hoc group of the histopathology subcommittee of the scientific services advisory group. Scottish Home and Health Department, Edinburgh 1987.

2 Department of Health and Social Security. Health services management cervical cancer screening. London: Department of Health, 1988. (DHSSHC(88) I/ cancer screening.

3 Health Service Division, Welsh Office. Cervical cytology screening services in Wales. Cardiff: National Health Service/Welsh Office Working Party, 1985.

4 Royal College of Obstetricians and Gynaecologists. Report of the intercollegiate working pary on cervical cytology screening. London: RCOG, 1987.

5 Duguid HLD, Duncan ID, Curry J. Screening for cervical intraepithelial neoplasia in Dundee and Angus 1962-1981 and its relationship with invasive cancer. Lancet 1985; ii:1053-6.

6 Duncan ID, ed. Guidelines for clinical practice and programme management. National co-ordinating network of the NHS cervical screening programme. Oxford: Oxford Regional Health Authority, 1992.

7 Fletcher A. Screening for cancer of the cervix in elderly women. Lancel 1990;335:97-9.

8 Cancer Research Campaign. Cancer of the cervix uteri. Oxford: Cancer Research Campaign, 1990. (Fact sheet 12.2.1990.)

9 Cancer Research Campaign. Cancer of the cervix uteri. Oxford: Cancer Research Campaign, 1990. (Fact Sheet 12.1.1990.)

10 International Association for Cancer Research Working Group on Valuation of Cervical Screening Programmes. Screening for squamous cervical cancer. Duration of low risk after negative cervical cytology and its implications for screening policies. $B M Y$ 1986;293:659-64.

(Accepted 4 February 1993)
University Department of Paediatrics, John Radcliffe Hospital, Oxford OX3 9DU Robert Booy, paediatric research fellow Sara Hodgson, paediatric research nurse E Richard Moxon, professor of paediatrics

\section{Department of Immunology} Helen Griffiths, clinical assistant in immunology Helen M Chapel, consultant immunologist

Correspondence to: Dr Booy.

BMF 1993;306:971-2

\section{Antibody persistence after accelerated immunisation against Haemophilus influenzae type b}

\author{
Robert Booy, Sara Hodgson, Helen Griffiths, \\ Helen M Chapel, E Richard Moxon
}

Haemophilus influenzae type $\mathrm{b}$ is a leading cause of bacterial meningitis in young children. As maternal antibodies decline infants become more susceptible to disease, and the peak incidence is at age 6-12 months.' Routine primary immunisation against $H$ influenzae type b was introduced in Britain in October 1992, with an accelerated schedule at 2,3 , and 4 months of age. A booster dose is not planned. Schedules for primary immunisation against $H$ influenzae type b in Europe and the United States are not completed until 5 or 6 months of age, and a booster dose is recommended in the second year of life.

We had previously immunised 107 infants according to the accelerated schedule with the conjugate vaccine polyribosylribitol phosphate-tetanus (PRP-T) (a polymer of ribosylribitol phosphate covalently linked to tetanus toxoid, Pasteur-Merieux) and established its immunogenicity. ${ }^{2}$ To determine if protective concentrations of antibody persist we followed up 95 infants until 1 year of age. The study was approved by the Central Oxford Research Ethics Committee.

\section{Patients, methods, and results}

The recruitment method was described previousiy. Polyribosylribitol phosphate-tetanus and diphtheriapertussis-tetanus immunisations were given separately by intramuscular injection at 2,3 , and 4 months. Venous blood was obtained for serological examination at 2 months, 5 months, and, in 95 infants, 1 year.

The concentration of total IgG antibody to polyribosylribitol phosphate was measured by enzyme linked immunosorbent assay (ELISA). ${ }^{2}$ Each sample taken at 1 year was assayed on the same plate as a previously collected sample from the same infant. The lower limit of sensitivity of the assay was $0.16 \mu \mathrm{g} / \mathrm{ml}$. Values below this were arbitrarily assigned the value $0.08 \mu \mathrm{g} / \mathrm{ml}$ for calculation of geometric mean titres.

At 1 year 89 infants had a serum polyribosylribitol phosphate antibody concentration $>0.15 \mu \mathrm{g} / \mathrm{ml}$ (figure). In 43 the concentration was $>1.0 \mu \mathrm{g} / \mathrm{ml}$. The geometric mean titre was $0.83 \mu \mathrm{g} / \mathrm{ml}$. Compared with

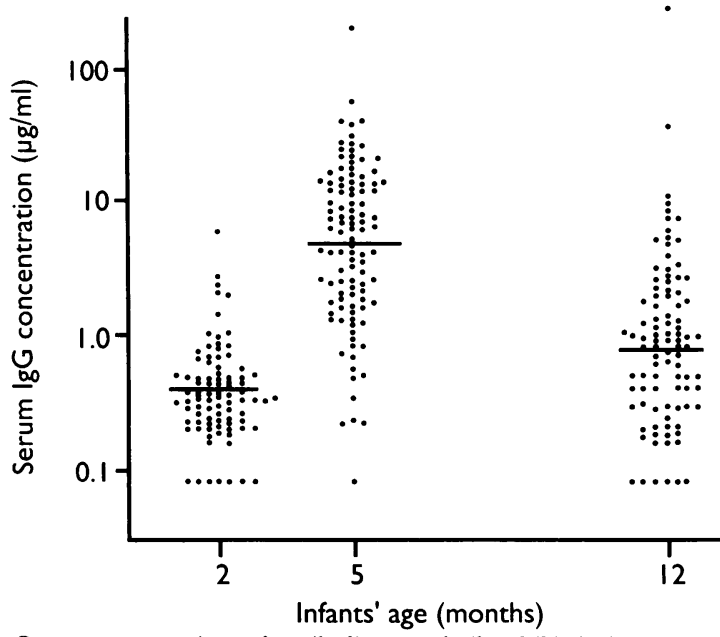

Serum concentrations of antibodies to polyribosylribitol phosphate in infants immunised at 2, 3, and 4 months (horizontal bars are geometric means)

the antibody concentrations measured at 5 months of age five infants showed at least a twofold rise and two of these showed more than fourfold rises at 1 year. None had clinical disease. One infant did not respond to primary immunisation (antibody concentration $<0.16 \mu \mathrm{g} / \mathrm{ml}$ at 5 months). A booster dose of the vaccine was given at 16 months, and one month later the antibody concentration was $3.4 \mu \mathrm{g} / \mathrm{ml}$.

\section{Comment}

We found that nearly all 1 year old infants immunised with polyribosylribitol phosphate-tetanus at 2,3 , and 4 months of age had serum antibody concentrations that are likely to be protective $(>0.15 \mu \mathrm{g} / \mathrm{ml})$. Without immunisation nearly all children of this age have antibody concentrations below $0 \cdot 15 \mu \mathrm{g} / \mathrm{ml}$ despite likely exposure to $H$ influenzae type b. ${ }^{3}$ The infant who failed to respond to primary immunisation was tested for immunodeficiency, but none was found and she responded well to a booster dose.

Immunisation of older infants-for example, according to the previous British schedule at ages 3, 5, and 9 months-produces higher antibody concentrations $^{3}$ and therefore prolongs protection if indeed prevention of disease depends on concentrations being maintained above a threshold. A booster in the second year of life is recommended in most countries with routine immunisation against $H$ influenzae type b. Our findings suggest that this may not be necessary. 
Since conjugate vaccines induce $\mathrm{T}$ cell dependency and thereby prime for a secondary immune response, immunised infants may be protected against $H$ influenzae type $\mathrm{b}$ irrespective of the concentration of circulating antibodies. In our study five infants had natural rises in their antibody concentrations in the absence of clinical disease. These and other results ${ }^{4}$ suggest that infants are primed by immunisation for a mature for age response to either the organism or cross reactive antigen.

In an open controlled prospective trial in the Oxford region we have shown the vaccine to be highly protective. ${ }^{5}$ Nationwide postmarketing surveillance (in collaboration with the British Paediatric Surveillance Unit) is examining the long term efficacy of the conjugate vaccine given to children at 2,3 , and 4 months without a booster dose in their second year.

\section{Clinical coding: completeness and accuracy when doctors take it on}

\section{Yeoh, H Davies}

\section{Central Middlesex Hospital, London NW10 7NS \\ C Yeoh, paediatric registrar $\mathrm{H}$ Davies, paediatric consultant}

Correspondence to:

Dr Davies.

$B M \mathcal{1 9 9 3 ; 3 0 6 : 9 7 2}$
Study samples and results

\begin{tabular}{|c|c|c|c|c|}
\hline & & 1990 & & 1991 \\
\hline $\begin{array}{l}\text { No of admissions } \\
\text { No (\%) analysed } \\
\text { No (\%) coded } \\
\text { No accurate } \\
\text { No partial } \\
\text { No inaccurate }\end{array}$ & & $\begin{array}{rr} & 152 \\
& 127(84) \\
& 37(29) \\
20 & \\
12 & \\
5 & \end{array}$ & $\begin{array}{l}\mathrm{p}<0.001 \\
\mathrm{p}<0.001\end{array}$ & $\begin{aligned} & 167 \\
& 117(70) \\
& 117(100) \\
99 & \\
17 & \\
1 & \end{aligned}$ \\
\hline No with diagnosis & Coded & $\begin{array}{c}1990 \\
\text { Assessed by reviewer } \\
\text { (No of diagnoses) }\end{array}$ & Coded & $\begin{array}{c}1991 \\
\text { Assessed by reviewer } \\
\text { (No of diagnoses) }\end{array}$ \\
\hline $\begin{array}{l}1 \\
2 \\
3 \\
4\end{array}$ & $\begin{array}{r}29 \\
8 \\
0 \\
0\end{array}$ & $\begin{array}{r}54 \\
51 \\
13 \\
9\end{array}$ & $\begin{array}{r}80 \\
31 \\
4 \\
2\end{array}$ & $\begin{array}{r}74 \\
37 \\
5 \\
1\end{array}$ \\
\hline
\end{tabular}

We thank Dr R T Mayon-White and Dr J A Macfarlane for their helpful comments on both the study's design and the manuscript, Dr J S Kroll for editorial advice, the families who agreed to participate in the study, and Mrs Carole Barr for typing the manuscript.

1 Howard AJ, Dunkin KT, Musser JM, Palmer SR. Epidemiology of Haemophilus influenzae type b disease in Wales. BMf 1991;303:441-5.

2 Booy R, Taylor SA, Dobson SRM, Isaacs D, Sleight G, Aitken S, et al. Immunogenicity and safety of PRP-T conjugate vaccine given according to the British accelerated immunisation schedule. Arch Dis Child 1992;67:475-8.

3 Tudor-Williams G, Frankland J, Isaacs D, Mayon-White RT, Macfarlane JA, Rees DG, et al. Haemophilus influenaze type b conjugate vaccine trial in Oxford: implications for the UK. Arch Dis Child 1989;64:520-4.

4 Madore DV, Johnson CL, Phipps DC, Pennridge Pediatric Associates, Popejoy LA, Eby R, et al. Safety and immunologic response to Haemophilus influenzae type b oligosaccharide-CRM 197 conjugate vaccine in 1-to-6 month old infants. Pediatrics 1990;85:331-7.

5 Booy R, Moxon ER, MacFarlane JA, Mayon-White RT, Slack MPE. Efficacy of Haemophilus influenzae type $B$ conjugate vaccine in Oxford region. [Letter] Lancet 1992;340:847.

(Accepted 22 December 1992)

\section{Comment}

Although only $70 \%$ of admissions in 1991 were analysed compared with $84 \%$ of admissions in 1990 , the large difference in coding levels could not be ascribed to this. Overall coding level in the children's ward in 1991 was $95 \%$ (Central Middlesex Hospital information department). The low level of coding in 1990 and its inaccuracy would prevent rational planning. The accuracy of coding in 1990 before medical staff took on responsibility for coding (20/37; $54 \%$ ) was slightly worse than that reported by Smith $(71 \%){ }^{.}$There were many reasons for the improvement. Medical staff are aware of the importance of accurate coding, and information technology has simplified the process as it is performed contemporaneously on the ward. It can also be attributed to greater clinical knowledge of medical staff.

The transfer of responsibility required motivating medical staff to change. There was initially reluctance and resentment, yet after training these problems resolved. Two problems emerged: the rapid turnover in children's wards, and training new or locum staff. To overcome the first problem the process had to respond rapidly. This was accomplished by using a second copy of the admission sheet to record diagnoses and procedures. These are taken on ward rounds to allow initial coding at the bedside. Information is transferred to the computer at the end of the ward round, obviating the need for notes, which are not always to hand. The second problem was solved by a program that provided a list of uncoded admissions. Even with that system uncoded admissions occasionally accumulated, particularly in neonatology. At those times a concerted effort by the whole team was required to bring the coding up to date.

Each department or hospital will need to develop its own solutions. We have used a large and comprehensive hospital system whereas others have designed their own for departmental use. ${ }^{2}$ Small may be beautiful, but we have shown that with energy and enthusiasm a department can exploit the possibilities of a much larger system and yet have "ownership." It is not our aim to supplant coding officers; their skills are needed to improve coding details. It must be recognised that fewer may be needed.

We conclude that participation of doctors in coding leads to greater accuracy, the benefit of case review, and creation of an accurate database for audit, research, and planning.

1 Smith MW. Hospital dischage diagnoses: how accurate are they and their ICD codes? NZ Med f 1989;102:507-8.

2 Smith AP. How to do it: design a clinical information system. BMf 1992;305: 415-7.

(Accepted 28 January 1993) 